\title{
ANALISIS PENOLAKAN DAN PENGULANGAN CITRA RADIOGRAFI PADA MODALITAS COMPUTED RADIOGRAPHY AGFA CR 35-X DI INSTALASI RADIOLOGI RSUD DR. R. GOETENG TAROENADIBRATA PURBALINGGA
}

\section{REJECT AND REPEAT ANALYSIS OF RADIOGRAPHIC IMAGES ON AGFA CR35-X COMPUTED RADIOGRAPHY UNIT IN RADIOLOGY INSTALLATION OF DR. R. GOETENG TAROENADIBRATA PURBALINGGA HOSPITAL}

\author{
Ikko Justian Fajarrissetyo $^{1)}$, Panji Wibowo Nurcahyo ${ }^{2)}$, Asri Indah Aryani ${ }^{3)}$ \\ 1) Pupuk Kalimantan Timur Prima Sangatta Hospital \\ ${ }^{2,3)}$ Health Polytechnics of Semarang-Indonesia \\ e-mail : justian23896@gmail.com
}

\begin{abstract}
Background: Reject film analysis program is a systematical process to count repeatedimages and determine the cause of the repeat, so it could be minimalized or banished even. This research aims to find out the reject percentage, cause of each reject percentage and the efforts to reduce it.

Method: This research was a quantitative model with descriptive approach. The research has been done in February, April and May of 2016. Data were obtained from observation, documentation and interview with three radiographers. Data was analyzed by Paretto's diagram to identify the influence of each cause.

Results: In February, April and May by orders the percentage of the radiographic images reject and repeat are 4,86\%, 4,65\%, 6,95\%. The factors of digital images reject and repeat were patient's position $(1,65 \%, 1,05 \%, 0,84 \%)$, uncorrect exposure value $(1,30 \%$, $0,98 \%, 1,87 \%)$, miscellaneous reasons $(0,35 \%, 0,38 \%, 0,28 \%)$, too narrow collimation $(0,26 \%, 0,68 \%, 0,47 \%)$, unsharpness $(0,17 \%$, $0,0 \%, 0,0 \%)$, digiscan fault $(0,09 \%, 0,30 \%, 0,84 \%)$ and $\mathrm{x}$-ray equipment's fault $(0,09 \%, 0,38 \%, 0,65 \%)$. Meanwhile in radiographic film factor, unwanted film $(0,61 \%, 0,30 \%, 0,67 \%)$, printer's fault $(0,35 \%, 0,08 \%, 0,95 \%)$, patient's position $(0,0 \%, 0,23 \%, 0,0 \%)$, miscellaneous reasons $(0,0 \%, 0,23 \%, 0,19 \%)$, too narrow collimation $(0,0 \%, 0,0 \%, 0,90 \%)$ and unsharpness $(0,0 \%, 0,08 \%, 0,0 \%)$. Conclusion: The efforts to reduce radiographic images reject and repeat were applying effective communications with patients and their family and taking notes whenever a failure occurs.
\end{abstract}

Keywords: reject film anaysis program, repeat film analysis program

\section{PENDAHULUAN}

Reject Analysis Program (RAP) adalah suatu program menganalisis berbagai penolakan film dan pengulangan foto dari proses pemeriksaan yang dilakukan di instalasi radiologi atau proses yang sistematik untuk mendata gambar yang diulang dan menentukan penyebab terjadinya pengulangan sehingga pengulangan dapat diminimalisasi dan bahkan dihilangkan. Analisa ini meliputi suatu film yang secara total tidak dapat diterima atau ditolak karena memiliki nilai diagnostik yang rendah. Sedangkan reject analysis adalah suatu metode yang digunakan untuk menentukan film yang ditolak (film reject), efektifitas biaya, konsistensi radiografer, dan bahan dalam menghasilkan radiograf yang berkualitas (Jenkins, 1980).

Tujuan utama dari program analisis pengulangan dan penolakan film radiografi adalah untuk melakukan tindakan perbaikan. Selanjutnya memberikan pengetahuan yang diperlukan untuk mengatur sebuah sistim yang akan memberikan sebuah analisis secara rinci terhadap penolakan film dan alasan dari penolakan film tersebut dan cara-cara pelaksanaannya (Lloyd, 2001). Program ini juga digunakan sebagai bahan evaluasi manfaat penggunaan modalitas Digital Radiography dan Computed Radiography (Jones, 2015).
Modalitas CR menghasilkan dua citra, yang pertama adalah citra digital radiografi. Merupakan istilah yang digunakan untuk mendeskripsikan gambar radiografi dalam bentuk digital yang dapat ditampilkan di layar monitor. Sistem pencitraan digital terdiri dari Computed Tomography (CT), Magnetic Resonance Imaging (MRI), Ultrasonography, dan Computed Radiography (Ballinger, 2012).

Penggunaan modalitas Computed radiography di Instalasi Radiologi RSUD dr. R. Goeteng Taroenadibrata Purbalingga belum mampu meminimalisir terjadinya penolakan atau reject serta repeat pada radiograf yang diproduksi. Baik dalam bentuk citra digital, maupun hard copy.

Faktor-faktor penyebab belum dapat diketahui, karena Instalasi Radiologi RSUD dr. R. Goeteng Taroenadibrata tidak memiliki program reject \& repeat film analysis yang teratur sejak pemasangan Computed Radiography (CR) pada tahun 2011.Berdasarkan hal tersebut, penulis tertarik untuk melakukan prosedur reject \& repeat film analysis program di Instalasi Radiologi RSUD dr. R. Goeteng Taroenadibrata Purbalingga, 


\section{METODE}

Jenis penelitian yang digunakan dalam penyusunan karya tulis ilmiah ini adalah kuantitatif dengan pendekatan deskriptif. Dilakukan pada bulan Februari, April, dan Mei 2016 di Instalasi Radiologi RSUD dr. R. Goeteng Taroenadibrata Purbalingga.

Tiga radiografer yang telah bekerja selama lebih dari lima tahun di Instalasi Radiologi RSUD dr. R. Goeteng Taroenadibrata Purbalingga. Metode pengambilan data dilakukan dengan cara observasi tidak terstruktur, wawancara mendalam dan dokumentasi.

Analisis data dilakukan dengan diagram Paretto dalam Papp (2006) dimana faktor-faktor penyebab dibuat grafik dan diurutkan dari faktor penyebab tertinggi ke yang paling rendah. Diagram paretto ini berupa tabulasi dari data pengamatan selama tiga bulan untuk melihat perkambangannya.

\section{HASIL}

Gambar 1 ditampilkan grafik Paretto yang diurutkan berdasarkan data penolakan bulan Februari. Diikuti oleh penolakan yang terjadi pada bulan April dan Mei pada faktor yang sama.

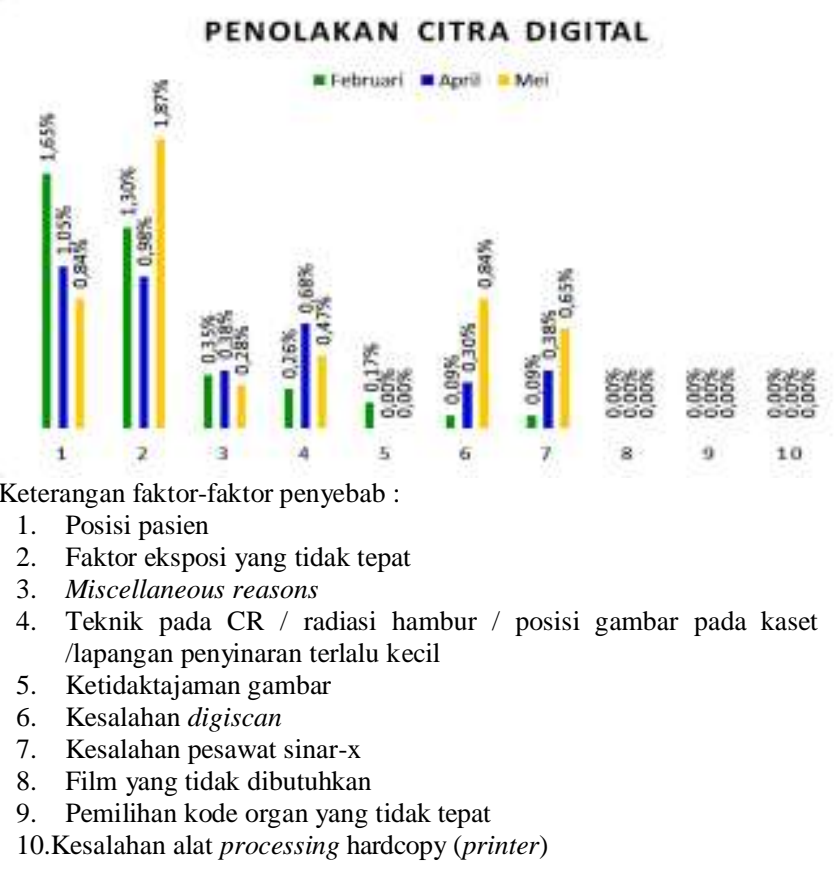

Gambar 1. Grafik Penolakan Citra Digital (Instalasi Radiologi RSUD dr.R. Goeteng Taroenadibrata Purbalingga)

Gambar 2 ditampilkan grafik Paretto yang diurutkan berdasarkan data penolakan bulan Februari. Diikuti oleh penolakan yang terjadi pada bulan April dan Mei pada faktor yang sama

\section{Penolakan Dan Pengulangan Citra Digital}

Pada bulan Februari 2016 menunjukkan adanya penolakan dan pengulangan pada citra digital sebanyak 3,91\% Hasil tersebut melebihi $1,91 \%$ dari batas maksimal yang ditetapkan oleh Kementerian Kesehatan. Pada bulan April menunjukkan adanya penolakan dan pengulangan pada citra digital sebanyak $3,75 \%$. Lebih besar $1,75 \%$ dari standar yang ditetapkan pemerintah, dan pada bulan Mei menunjukkan adanya penolakan dan pengulangan pada citra digital sebanyak 4,95\% yang lebih besar 2,95\% dari standar di Keputusan Menteri Kesehatan nomor: 129/Menkes/SK/II/2008 tentang standar minimal Rumah Sakit yaitu $\leq 2 \%$.

\section{PENOLAKAN FILM RADIOGRAFI}

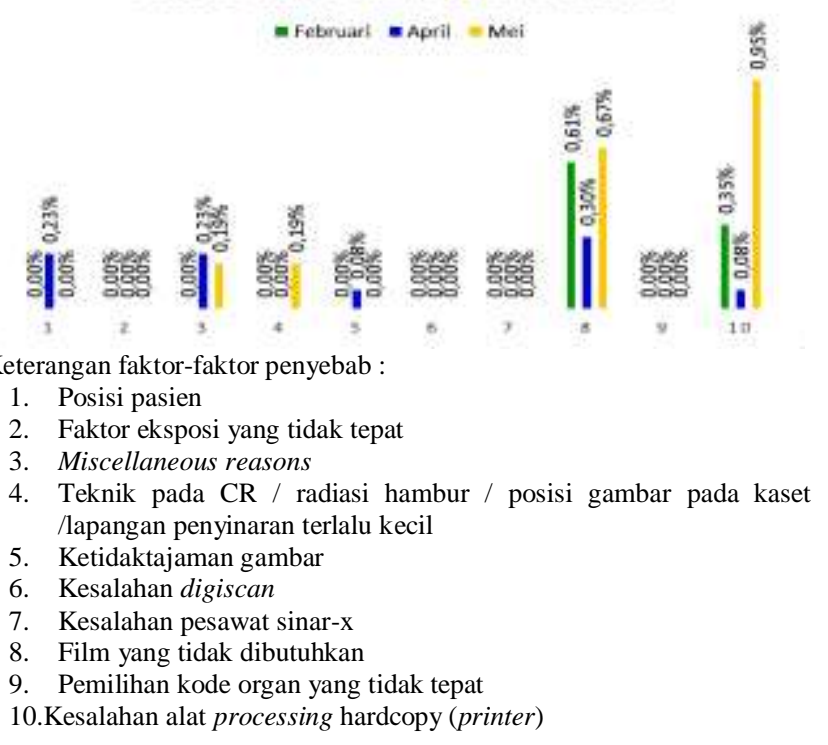

Gambar 2. Grafik Penolakan Citra Digital (Instalasi Radiologi RSUD dr. R. Goeteng Taroenadibrata Purbalingga)

\section{Penolakan dan Pengulangan Film Radiografi}

Terdapat $0,95 \%$ penolakan pada film radiografi yang telah dicetak di bulan Februari., dan 0,90\% pada bulan April. Pada periode ini lebih kecil dari $2 \%$ seperti yang ditetapkan Kementerian Kesehatan. Pada bulan Mei prosentasenya sebanyak 2,00\% sesuai standar pada KMK nomor :129/Menkes/SK/II/2008 tentang standar minimal Rumah Sakit.

Prosentase dari masing-masing faktor penyebab menentukan pengaruh suatu faktor terhadap penolakan yang terjadi pada setiap bulannya. Seperti yang tampak pada diagram paretto yang diurutkan berdasarkan data bulan Februari, April, dan Mei. Dari hasil tersebut, dua faktor yang paling tinggi prosentasenya digunakan sebagai dasar pembuatan usaha perbaikan. Sesuai dengan kesepakatan penulis dengan pihak Instalasi Radiologi, data yang digunakan adalah data pengamatan pada bulan April, dan akan dievaluasi menggunakan data bulan Mei. Dalam hal ini pada citra digital, faktor yang paling tinggi adalah posisi pasien, dan faktor eksposi yang tidak tepat. Pada film radiografi yang telah dicetak adalah kesalahan processing hardcopy atau printer, dan film yang tidak berguna. 


\section{DISKUSI}

\section{Prosentase penolakan dan pengulangan citra radiografi pada modalitas Computed Radiography Agfa CR 35-X di Instalasi Radiologi RSUD dr. R. Goeteng Taroenadibrata Purbalingga}

Penolakan dan pengulangan citra digital data yang didapatkan pada bulan Februari menunjukkan adanya penolakan dan pengulangan pada citra digital sebanyak 3,91\% Hasil tersebut melebihi $1,91 \%$ dari batas maksimal yang ditetapkan oleh Kementerian Kesehatan. Pada bulan April menunjukkan adanya penolakan dan pengulangan pada citra digital sebanyak 3,75\%. Lebih besar $1,75 \%$ dari standar yang ditetapkan pemerintah, dan pada bulan Mei menunjukkan adanya penolakan dan pengulangan pada citra digital sebanyak 4,95\% yang lebih besar 2,95\% dari standar di Keputusan Menteri Kesehatan nomo: 129/Menkes/SK/II/2008 tentang standar minimal Rumah Sakit yaitu $\leq 2 \%$.

Penolakan dan pengulangan film radiografi terdapat 0,95\% penolakan pada film radiografi yang telah dicetak di bulan Februari., dan 0,90\% pada bulan April. Pada periode ini lebih kecil dari $2 \%$ seperti yang ditetapkan Kementerian Kesehatan. Pada bulan Mei prosentasenya sebanyak 2,00\% sesuai standar pada KMK nomor : 129/Menkes/SK/II/2008 tentang standar minimal Rumah Sakit.

Prosentase masing-masing penyebab penolakan dan pengulangan citra radiografi pada modalitas Computed Radiography Agfa CR 35-X di Instalasi Radiologi RSUD dr. R. Goeteng Taroenadibrata Purbalingga

Prosentase dari masing-masing faktor penyebab menentukan pengaruh suatu faktor terhadap penolakan yang terjadi pada setiap bulannya. Seperti yang tampak pada diagram paretto yang diurutkan berdasarkan data bulan Februari, April, dan Mei. Faktor-faktor penyebab dari yang paling tinggi ke yang paling rendah pada citra digital adalah posisi pasien $(1,65 \%, 1,05 \%, 0,84 \%)$, faktor eksposi yang tidak tepat $(1,30 \%, 0,98 \%, 1,87 \%)$, miscellaneous reasons $(0,35 \%, 0,38 \%, 0,28 \%)$, teknik pada CR / radiasi hambur / posisi gambar pada kaset / lapangan penyinaran terlalu kecil $(0,26 \%, 0,68 \%, 0,47 \%)$, ketidaktajaman gambar $(0,17 \%$, $0,0 \%, 0,0 \%)$, kesalahan digiscan $(0,09 \%, 0,30 \%, 0,84 \%)$, dan kesalahan pesawat sinar-x $(0,09 \%, 0,38 \%, 0,65 \%)$.

Lalu pada film radiografi yang menjadi faktor paling tinggi ke yang paling rendah adalah film yang tidak dibutuhkan $(0,61 \%, 0,30 \%, 0,67 \%)$, kesalahan alat processing hardcopy atau printer $(0,35 \%, 0,08 \%, 0,95 \%)$, posisi pasien $(0,0 \%, 0,23 \%, 0,0 \%)$, Miscellaneous reasons $(0,0 \%, 0,23 \%$, $0,19 \%$ ), teknik pada $\mathrm{CR} /$ radiasi hambur / posisi gambar pada kaset / lapangan penyinaran terlalu kecil $(0,0 \%, 0,0 \%, 0,90 \%)$, dan ketidaktajaman gambar $(0,0 \%, 0,08 \%, 0,0 \%)$.

Dari hasil tersebut, dua faktor yang paling tinggi prosentasenya digunakan sebagai dasar pembuatan usaha perbaikan. Sesuai dengan kesepakatan penulis dengan pihak Instalasi Radiologi, data yang digunakan adalah data pengamatan pada bulan April, dan Akan dievaluasi menggunakan data bulan Mei. Dalam hal ini pada citra digital, faktor yang paling tinggi adalah posisi pasien, dan faktor eksposi yang tidak tepat. Pada film radiografi yang telah dicetak adalah kesalahan processing hardcopy atau printer, dan film yang tidak berguna.

Upaya yang dilakukan untuk mengurangi penolakan dan pengulangan citra radiografi pada modalitas Computed Radiography Agfa CR 35-X di Instalasi Radiologi RSUD dr. R. Goeteng Taroenadibrata Purbalingga

Upaya-upaya yang dilakukan ditentukan berdasarkan faktor-faktor dominan yang menyebabkan penolakan dan pengulangan. Dimana faktor dominan penyebab penolakan dan pengulangan pada citra digital adalah faktor posisi pasien dengan meningkatkan komunikasi yang efektif dengan pasien, maupun pengantar pasien. Selain itu, pemanfaatan alat-alat imobilisasi dimaksimalkan untuk pasien yang tidak memiliki pengantar baik keluarga ataupun perawat. Lalu untuk mengurangi penolakan dan pengulangan karena faktor eksposi yang tidak tepat adalah dengan mencatat faktor eksposi yang menghasilkan gambaran yang baik beserta ciri-ciri ketebalan objeknya. Selain itu, tabel panduan faktor eksposi yang ada juga selalu dievaluasi di setiap pertemuan internal yang diadakan.

Usaha yang dilakukan untuk mengurangi penolakan dan pengulangan pada film radiografi yang telah dicetak adalah dengan membersihkan printer. Pembersihan dilakukan pada bagian luar printer dan bagian dalam atau pada roller-roller yang ada pada printer. Lalu untuk mengurangi film yang tidak dibutuhkan adalah dengan mematikan printer saat pencetakan yang tidak terkendali terjadi. Tetapi kedua hal ini hanya bisa mengatasi saat kejadian terjadi, dan tidak dapat digunakan untuk mencegah agar tidak terjadi di kemudianhari.

\section{SIMPULAN}

Pada bulan Februari, April dan Mei secara berturutturut prosentase penolakan dan pengulangan citra radiografinya adalah 4,86\%, 4,65\%, 6,95\%. Dengan prosentase penolakan dan pengulangan citra digital sebesar $3,91 \%, 3,75 \%$, dan 4,95\%. Lalu prosentase penolakan pada film radiografi (hardcopy) adalah $0,95 \%, 0,90 \%$ dan $2,00 \%$. Terjadi kenaikan prosentase yang disebabkan kesalahan peralatan yang digunakan yang meningkat.

Faktor-faktor penyebab penolakan dan pengulangan pada citra digital di bulan Februari, April, dan Mei adalah posisi pasien $(1,65 \%, 1,05 \%, 0,84 \%)$, faktor eksposi yang tidak tepat $(1,30 \%, 0,98 \%, 1,87 \%)$, miscellaneous reasons $(0,35 \%, 0,38 \%, 0,28 \%)$, teknik pada CR / radiasi hambur / posisi gambar pada kaset / lapangan penyinaran terlalu kecil $(0,26 \%, 0,68 \%, 0,47 \%)$, ketidaktajaman gambar $(0,17 \%, 0,0 \%, 0,0 \%)$, kesalahan digiscan $(0,09 \%, 0,30 \%$, $0,84 \%)$, dan kesalahan pesawat sinar-x $(0,09 \%, 0,38 \%$, $0,65 \%)$. Pada film radiografi yang menjadi faktor paling tinggi ke yang paling rendah adalah film yang tidak dibutuhkan $(0,61 \%, 0,30 \%, 0,67 \%)$, kesalahan alat processing hardcopy atau printer $(0,35 \%, 0,08 \%, 0,95 \%)$, posisi pasien $(0,0 \%$, $0,23 \%, 0,0 \%)$, Miscellaneous reasons $(0,0 \%, 0,23 \%, 0,19 \%)$, teknik pada CR / radiasi hambur / posisi gambar pada kaset / lapangan penyinaran terlalu kecil $(0,0 \%, 0,0 \%, 0,90 \%)$, dan ketidaktajaman gambar $(0,0 \%, 0,08 \%, 0,0 \%)$. Upaya yang dilakukan adalah dengan komunikasi kepada pasien dan 
keluarganya, dan melakukan pencatatan setiap terjadi kesalahan.

\section{DAFTAR PUSTAKA}

Agfa Healthcare. 2010. Agfa Digital Imaging: Computed Radiography. agfahealthcare.com: 9 Maret 2016

Bushong, Stewart C. 2001. Radiologic Science for Technologist. Seventh Edition, St. Louis: Mosby.

Ballinger, P.W. 2012. Merill's Atlas of Radiographic Position and Radiographic Procedures, Volume Two. London : Mosby Co.

Carlton, R Richard, and Arlene M, Adler. 2001. Principer of Radiographic Image: An Art and Science, Third Edition. Dalman: USA.

Jenkins, D. 1980. Radiographic Photographic and Imaging Processing, Rockville. Maryland: An Aspen Publication Aspen Publishers Inc.

Kepmenkes RI. 2009. UU Republik Indonesia No. 44, Tentang Rumah Sakit, Jakarta

Leung, Chuen Yung. 2012. Artifacts in Digital Radiography (DDR\&CR). China

Llyod, Peter J. 2001. Quality Assurance Workbook for Radiographer and Radiological Technologist, of Lecture (retired). School of Medical Radiation: University of South Australia

Jones, A. Kylie, and Co. 2015. Ongoing Quality Control in Digital Radiography: Report of AAPM Imaging Physics Comitee Task Group 151. Houston, Texas: American Association of Physists in Medicine

Papp, Jeffrey. 2006. Quality Management in the Imaging Science, Processor of Physics and Diagnostic Iaging Controlling of Dupage Glen Ellyn. Illinois: Moby Inc.

Rimadhani, Aditya. 2014. Analisa Faktor Penyebab Penolakan Citra Digital Pada Modalitas Computed Radiography (CR) di Instalasi Radiologi RSUD dr. R. Goeteng Purbalingga, Purwokerto. Poltekkes Kemenkes Semarang, Jurusan Teknik Radiodiagnostik dan Radioterapi.

Purnomo, Adi. 2014. Analisa Penolakan Film di Instalasi Radiologi Rumah Sakit Umum Daerah $\mathrm{Hj}$. Anna Lasmanah Banjarnegara, Purwokerto. Poltekkes Kemenkes Semarang, Jurusan Teknik Radiodiagnostik dan Radioterapi

Putri, Tyas Annisha. 2015. Analisa Penolakan Film Radiografi di Instalasi Radiologi RSUD dr. Soesilo Slawi, Purwokerto: Poltekkes Kemenkes Semarang, Jurusan Teknik Radiodiagnostik dan Radioterapi

Weatherburn, G C. 1999. A comparison of image reject rates when using $1 \mathrm{~m}$, hard copy computed radiography and soft copy images on picture archiving and communication systems (PACS) workstations. London: The British Institute of Radiology 